\title{
Vitamin D Deficiency: Prevalence and Association with Intrathoracic Tuberculosis in Indian Children
}

\author{
Priyatharshini Parameswaran ${ }^{1}$ - Pankaj C Vaidya ${ }^{1}$ - Savita Verma Attri ${ }^{1}$ - Suresh Kumar Angurana ${ }^{1}$. \\ Pandiarajan Vignesh $^{1} \cdot$ Meenu Singh ${ }^{1}$
}

Received: 9 February 2020 / Accepted: 13 May 2020 / Published online: 28 May 2020

(C) Dr. K C Chaudhuri Foundation 2020

To the Editor: Tuberculosis (TB) is a major public health problem in developing countries. Active form of vitamin D [1, 25dihydroxy vitamin $\mathrm{D} ; 1,25(\mathrm{OH}) \mathrm{D}]$ has been shown to affect innate immunity by modulating macrophage functions, upregulating antimicrobial peptide cathelicidin, and enhancing killing of intracellular organisms. In view of immunomodulatory effect of vitamin $\mathrm{D}$, vitamin $\mathrm{D}$ deficiency (VDD) has been linked to TB in adults, but literature is scarce in children $[1,2]$. We investigated the prevalence of VDD in children with intrathoracic TB and its relationship with the type of intrathoracic TB.

A cross-sectional observational study was conducted at a tertiary care teaching hospital in North-India over a period of $1 \mathrm{y}$. Children of either sex $<12 \mathrm{y}$ of age with the diagnosis of intrathoracic TB [as per the Revised National Tuberculosis Control Programme (RNTCP) pediatric guidelines] were enrolled prior to starting anti-tubercular therapy (ATT) [3, 4]. Ethical approval was obtained from the Institutional Ethics Committee and children were enrolled after written informed consent from the parents. Levels of 25-dihydroxy vitamin D $[25(\mathrm{OH}) \mathrm{D}]$ were measured by enzyme immunoassay before starting ATT. Depending on 25(OH)D level, children were classified into three categories: vitamin D deficiency: $25(\mathrm{OH}) \mathrm{D}$ levels $<20 \mathrm{ng} / \mathrm{ml}$; vitamin D insufficiency: $25(\mathrm{OH}) \mathrm{D}$ levels 20-30 ng/ml; and vitamin D sufficiency: 25(OH)D levels $>30 \mathrm{ng} / \mathrm{ml}[5]$.

Forty children ( $55 \%$ males, $n=22$ ) were enrolled with median (IQR) age of 5 (1.5-9.4) y. Based on chest radiograph findings, $7.5 \%(n=3)$ cases had primary pulmonary complex (PPC), $87.5 \%(n=35)$ had progressive primary disease (PPD)

\section{Pankaj C Vaidya}

dr_pcv@yahoo.com

1 Department of Pediatrics, Advanced Pediatrics Centre (APC), Postgraduate Institute of Medical Education and Research (PGIMER), Chandigarh 160012, India and 5\% $(n=2)$ had pleural effusion (PE). Baseline 25(OH)D levels were 12.8 (8-21) [median (IQR)] ng/ml.

Vitamin D deficiency, insufficiency and sufficiency was noted in 70\% (28/40), 17.5\% (7/40) and 12.5\% (5/40) children, respectively. VDD was noted in $33.3 \%$ (1/3) cases with PPC, 74.3\% (26/35) in PPD and 50\% (1/2) in PE ( $\mathrm{p}=\mathrm{NS})$. We did not observe any significant association of VDD and serum levels of 25(OH)D with different types of intrathoracic TB (PPC, PPD and $\mathrm{PE}$ ). Therefore, this study concluded that the prevalence of VDD was high in children with intrathoracic TB but there was no relation between VDD and type of intrathoracic TB.

Acknowledgements The authors acknowledge Ms. Mini Tageja (Junior Laboratory Technician) for helping in the laboratory tests and in compiling the data.

\section{Compliance with Ethical Standards}

Conflict of Interest None.

\section{References}

1. Khandelwal D, Gupta N, Mukherjee A, et al. Vitamin D levels in Indian children with intrathoracic tuberculosis. Indian J Med Res. 2014;140:531-7.

2. Buonsenso D, Sali M, Pata D, et al. Vitamin D levels in active TB, latent TB, non-TB pneumonia and healthy children: A prospective observational study. Fetal Pediatr Pathol. 2018;37:337-47.

3. Kumar A, Gupta D, Nagaraja SB, et al. Updated national guidelines for pediatric tuberculosis in India, 2012. Indian Pediatr. 2013;50:301-6.

4. Central TB Division, Government of India. Revised National Tuberculosis Control Programme: Technical and Operational Guidelines for Tuberculosis Control in India. New Delhi, India: Government of India, 2016. Available at: https://www.tbcindia. gov.in/showfile.php?lid=3216. Accessed April 30, 2020.

5. Angurana SK, Angurana RS, Mahajan G, Kumar N, Mahajan V. Prevalence of vitamin D deficiency in apparently healthy children in North India. J Pediatr Endocrinol Metab. 2014;27:1151-6.

Publisher's Note Springer Nature remains neutral with regard to jurisdictional claims in published maps and institutional affiliations. 